\title{
Comparison of R744 and R134a heat transfer coefficients during flow boiling in a horizontal circular smooth tube
}

\author{
R. Mastrullo ${ }^{1}$, A.W. Mauro ${ }^{1}$, A. Rosato ${ }^{1}$, G.P. Vanoli ${ }^{2}$ \\ ${ }^{1}$ D.E.TE.C., Facoltà di Ingegneria, Università degli Studi di Napoli Federico II, p.le Tecchio 80, 80125 Napoli, Italy, \\ Fax number: +39 (0)81 2390364, E-mail: antonio.rosato@unina.it
}

${ }^{2}$ Dipartimento di Ingegneria, Università degli Studi del Sannio, corso Garibaldi 107, Palazzo dell'Aquila Bosco Lucarelli, 82100 Benevento, Italy

\begin{abstract}
In last and recent years new regulamentations and protocols concerning the environmental impact of refrigerants have led to the research of new environmental friendly refrigerants. In this contest the carbon dioxide (R744) is considered as one of the most promising substitute of the actually most widely used refrigerant in commercial refrigeration: R134a. However, some technical and thermodynamic problems avoid a widespread use of R744 in refrigeration applications. Referring to the performances of R744 in refrigerating applications, they are influenced by the design of components. In order to study the heat transfer characteristics at refrigerant side during flow boiling of R744 and to compare its behaviour to that of R134a, the authors carried out experiments in several working conditions usually encountered in commercial refrigeration. In this work are presented the experimental results of heat transfer coefficients for R744 and a comparison with those for R134a in the whole range of vapour qualities for a heat flux equal to 10 $\mathrm{kW} / \mathrm{m}^{2}$ varying the mass flux between 200 and $350 \mathrm{~kg} / \mathrm{m}^{2} \mathrm{~s}$ and the saturation temperature between $-8.0^{\circ} \mathrm{C}$ and $+5.0^{\circ} \mathrm{C}$.
\end{abstract}

\section{Key words}

R134a, R744, heat transfer coefficient, flow-boiling, evaporator, refrigeration.

\section{Introduction}

Over the last decades, the refrigeration, air conditioning and heat pump industry has been forced through major changes caused by restrictions on refrigerants [1]. During last years, new trends in the use of refrigerants established depending on the application field. In several applications of domestic, commercial and industrial refrigeration the largest demand of refrigerant is for R134a [2]. For the future, no restriction in its use is imposed by the actual regulations, with except for the mobile air-conditioning systems. However, there is growing concern about future use of HFC refrigerants due to their impact on climate change. For this reason there is an increasing interest in technology based on ecologically safe natural refrigerants. Among these, carbon dioxide is seen today as one of the most promising refrigerants [3], because it is an ozone friendly, with negligible GWP, non toxic, non flammable fluid, with special thermodynamic and transport properties.

Taking into account that the climate change is influenced by energy consumption during the lifetime of refrigerating equipment, the essential option to lower the environmental impact is to improve the energy efficiency of R744 systems. To maximize the performances of a vapor compression plant, a proper design of each component is necessary. Among the components which influence the cycle efficiency, the evaporator is of particular importance. To optimise the design of evaporators, the accurate knowledge of heat transfer coefficients and pressure drops are fundamental. Recently, our research group compared the experimental R744 pressure gradients with those obtained with R134a at similar operating conditions [4].

About the study of R134a flow boiling, several works are available in literature covering different operating conditions. Nevertheless, few papers are available for inner diameters from 5 to $7 \mathrm{~mm}$, a range of diameter largely used in refrigeration. Besides, there is a lack of experimental results for evaporating temperatures lower than $0{ }^{\circ} \mathrm{C}$. A lot of experimental studies have been carried out in recent years to measure the $\mathrm{CO}_{2}$ two-phase heat transfer coefficients during flow boiling. Nevertheless, more accurate local heat transfer data are still needed. In fact, carbon dioxide showed a very 
different behaviours during evaporation in comparison to the conventional refrigerants. As a consequence the heat transfer prediction methods developed for low and medium pressure refrigerants, generally underpredict the experimental data of $\mathrm{CO}_{2}$. Besides some discrepancies can be noticed among the experimental results obtained by different researchers.

In this work new and accurate local heat transfer coefficients of R134a and R744 during flow boiling have been measured and compared in order to evaluate the influence of the thermodynamic and transport properties. The test section adopted is a smooth, horizontal, circular, stainless steel tube with an inner diameter equal to 6.00 $\mathrm{mm}$.

The tests reported cover continuously a wide range of operating conditions often encountered in dry-expansion evaporators in order to evaluate the dependence of the heat transfer coefficients on the vapor quality, the saturation temperature, the refrigerant mass flux and the heat flux.

In this paper, we present a comparison between experimental data obtained in similar operating conditions.

Concerning R134a, 40 operating conditions were investigated obtaining 254 experimental points varying the refrigerant mass flux from 197 to $472 \mathrm{~kg} / \mathrm{m}^{2} \mathrm{~s}$, the saturation temperature from $-8.8{ }^{\circ} \mathrm{C}$ to $19.9^{\circ} \mathrm{C}$ and the heat flux from 8.5 to $20.1 \mathrm{~kW} / \mathrm{m}^{2}$. With $\mathrm{R} 744$, we varied the refrigerant mass flux within the range from 200 to $349 \mathrm{~kg} / \mathrm{m}^{2} \mathrm{~s}$, the evaporating temperatures within the range from -7.8 to $5.8{ }^{\circ} \mathrm{C}$ and the heat flux within the range from 10.0 to $20.6 \mathrm{~kW} / \mathrm{m}^{2}$. The local heat transfer coefficient of carbon dioxide have been experimentally measured in 18 different operating conditions obtaining 184 experimental points.

\section{Experimental apparatus}

A schematic view of the plant is shown in Figure 1. The experimental apparatus allows to measure simultaneously the local heat transfer coefficients (h) and pressure gradients during flow boiling. At this scope two test sections were installed: the first one is diabatic (DTS), while the second one is adiabatic (ATS). The refrigerant loop consists of a magnetic gear pump, a pre-heater $(\mathrm{PH})$, an adiabatic and a diabatic test section, a shell-and-tube heat exchanger, a brazed plate heat exchanger and a tubein-tube sub-cooler.

The magnetic gear pump drives the fluid coming from the liquid reservoir. The refrigerant mass flux can be modified varying the electric motor speed by an inverter. The refrigerant, in sub-cooled conditions, passes first through the pre-heater where heat is supplied to the fluid by four fibreglass heating tapes (each one has a nominal power of $830 \mathrm{~W}$ at $240 \mathrm{~V}$ (AC)); changing the voltage it is possible to modify the thermal power and to obtain the desired quality at the diabatic test section inlet. After the pre-heater, the fluid flows through the diabatic test section. Upstream the latter, a straight tube of $60.0 \mathrm{~cm}$ length allows the fully development of the flow.

The diabatic test section is a smooth, horizontal, circular, stainless steel (type 304) tube with an inner radius of $3.00 \pm 0.05 \mathrm{~mm}$, a outer radius of $4.00 \pm 0.05 \mathrm{~mm}$ and a length of $1200.0 \pm 0.5 \mathrm{~mm}$ at $20{ }^{\circ} \mathrm{C}$ and 1.0 bar. The thermal power is provided to the fluid by Joule effect by a feed current device.

After the evaporation, the refrigerant passes the adiabatic test section and then condenses in a shell-and-tube heat exchanger and in a brazed plate heat exchanger. Before returning to the pump, the refrigerant is sub-cooled in a tube-in-tube heat exchanger. The coolant is an auxiliary fluid (TEMPER) contained in a storage tank of $200 \mathrm{dm}^{3}$. It can be chilled down to $-30{ }^{\circ} \mathrm{C}$ by a R404A auxiliary refrigerating plant and it is circulated by a magnetic gear pump connected to an inverter. By adjusting the refrigerant charge, the TEMPER inlet temperature and mass flow rate, it is possible to modify and hold constant the refrigerant evaporating pressure in the test section. To avoid heat gains, heavy insulation was provided by an elastomeric insulator $\left(\mathrm{k}=0.035 \mathrm{~W} / \mathrm{mK}\right.$ at $\left.0.0{ }^{\circ} \mathrm{C}\right)$ for the two test sections, shell-and-tube heat exchanger, the tubein-tube sub-cooler, the liquid reservoir, the tubes and the tube fittings; by a $32 \mathrm{~mm}$ layer of cellular insulator $\left(\mathrm{k}=0.040 \mathrm{~W} / \mathrm{mK}\right.$ at $\left.40{ }^{\circ} \mathrm{C}\right)$ for the plate heat exchanger and by $5 \mathrm{~cm}$ layer of rock wool insulator $(\mathrm{k}=0.075 \mathrm{~W} / \mathrm{mK}$ at $300{ }^{\circ} \mathrm{C}$ ) for the preheater.

\section{Data acquisition and data reduction}

For data acquisition and storage, a personal computer connected with a 16 bit resolution data acquisition system, provided with a software for monitoring experimental values, is used. The logging of signals from all the sensors is performed on all the channels for $100 \mathrm{~s}$ with $1.0 \mathrm{~Hz}$ acquisition frequency and the average values of each channel are stored. If the deviation of each value from its average value is lower than a fixed quantity, steady-state conditions are assumed.

To run the calculations of the local heat transfer coefficient and vapour quality the following assumptions are made:

- steady-state conditions;

- the refrigerating loop is adiabatic to the surroundings;

- the tube of the diabatic test section is homogeneous and isotropic, so that the heat generation inside the tube due to the Joule effect can be safely considered uniform;

- there are no electric leakages from the diabatic test section to the remaining part of the loop, since dielectric fittings are used at the test section inlet and outlet;

- the effect of axial conduction into the diabatic test section to the tube wall temperature measurements is negligible;

- heating power of the pre-heater and of the diabatic test section is completely transferred to the fluid;

- the heat flux at the inner wall of the diabatic test section is uniform.

The local heat transfer coefficient is measured in the section M, far away $200.0 \pm 0.05 \mathrm{~mm}$ from the exit of the diabatic, by the Newton equation: 
$\mathrm{h}=\frac{\dot{\mathrm{Q}}_{\mathrm{DTS}}}{2 \pi \mathrm{r}_{\mathrm{i}, \mathrm{DTS}} \mathrm{L}_{\mathrm{DTS}}\left(\mathrm{t}_{\mathrm{w}, \mathrm{i}}-\mathrm{t}_{\mathrm{sat}}\right)}=\frac{\mathrm{q}}{\left(\mathrm{t}_{\mathrm{w}, \mathrm{i}}-\mathrm{t}_{\mathrm{sat}}\right)}$

Heating power (Q) provided to the fluid is calculated measuring the voltage $\mathrm{V}_{\text {DTS }}$ between the inlet and the exit of the tube by an electrical voltage transducer; the electrical resistance of tube $\mathrm{R}_{\mathrm{DTS}}$ from the calibration certificate is $0.037121 \Omega \pm 0.056 \mathrm{~m} \Omega$ at $-4.90{ }^{\circ} \mathrm{C}$ and $0.039159 \pm 0.059 \mathrm{~m} \Omega$ at $35.00{ }^{\circ} \mathrm{C}$. $\mathrm{t}_{\text {sat }}$ is calculated from the absolute pressure $p_{\text {sat }}$ at the section $\mathrm{M}$, which is measured by a piezoelectric absolute pressure transducer. $\mathrm{t}_{\mathrm{w}, \mathrm{i}}$ is calculated from the measured outside wall temperature $t_{\mathrm{w}, \mathrm{o}}$ by applying the one-dimensional, radial, steady-state heat conduction equation for a hollow cylinder with a uniform heat generation. $t_{\mathrm{w}, \mathrm{o}}$ is measured with four four-wire Pt100 resistance thermometers mounted on the top, the bottom, the left and the right sides of the tube in order to taking into account the liquid and vapour spatial distribution. Four values of $t_{w, i}$ and, therefore, four local heat transfer coefficients $h_{\text {top }}, h_{\text {bottom, }}$ $\mathrm{h}_{\text {left }}, \mathrm{h}_{\text {right }}$ are obtained.

At the section $\mathrm{M}$, the vapour quality is obtained from the local saturation pressure $\mathrm{p}_{\mathrm{sat}}$ and the specific enthalpy $\mathrm{i}_{\mathrm{M}}$; the latter is calculated by an energy balance between the inlet of the pre-heater and the section $\mathrm{M}$ :

$\mathrm{i}_{\mathrm{M}}=\mathrm{i}_{\mathrm{in}, \mathrm{PH}}+\frac{\dot{\mathrm{Q}}_{\mathrm{PH}}}{\dot{\mathrm{m}}}+\frac{\dot{\mathrm{Q}}_{\mathrm{in}, \mathrm{DTS}-\mathrm{M}}}{\dot{\mathrm{m}}}$

The refrigerant mass flow rate $\dot{m}$ is measured by a Coriolis effect mass flow meter working in the liquid line.

The specific enthalpy at the inlet of the pre-heater is evaluated from the absolute pressure $\mathrm{p}_{\mathrm{in}, \mathrm{PH}}$ and the temperature $t_{\text {in,PH. }}$. The heating power provided to the refrigerant in the pre-heater is measured with a wattmeter, while the heating power supplied to the fluid between the diabatic test section inlet and the measurement section is determined as $R_{\text {in,DTS-M }} \frac{V_{\text {DTS }}^{2}}{R_{\text {DTS }}^{2}}$, where $R_{\text {in,DTS-M }}$ is the electrical resistance of the considered part of the heated channel $(0.030209 \Omega$ $\pm 0.045 \mathrm{~m} \Omega$ at $-4.90{ }^{\circ} \mathrm{C}$ and $0.032168 \pm 0.045 \mathrm{~m} \Omega$ at $34.60{ }^{\circ} \mathrm{C}$ ). The uncertainties for the local heat transfer coefficient and for the vapor quality at section $\mathrm{M}$ were calculated according to the single-sample uncertainty analysis suggested by Moffat [5]. The relative measurement uncertainty in the evaluation of the local heat transfer coefficient is always lower than $7.0 \%$.

The plotted value of heat transfer coefficient $h_{M}$ derives from the arithmetic mean of the arithmetic mean of the 100 values of $h_{\text {top }}, h_{\text {bottom }}, h_{\text {left }}, h_{\text {right }}$ calculated.

All the thermodynamic properties are calculated by the software REFPROP [6].

Preliminary tests have been carried out in order to verify the reliability and the repeatability of the measurements.

\section{Experimental results}

Figure 2 a) shows the heat transfer coefficients (HTCs) of R134a as a function of vapour quality varying the mass flux between 200 and $350 \mathrm{~kg} / \mathrm{m}^{2} \mathrm{~s}$ for a heat flux equal to $10.0 \mathrm{~kW} / \mathrm{m}^{2}$ and a saturation temperature of $5.0^{\circ} \mathrm{C}$. It is evident that the HTCs increase with vapour quality. As known, during evaporation the heat transfer at the wall is due to two superimposing effects: the nucleation of vapour bubbles and the convection. The convective contribution is influenced by the mean fluid velocity and the two-phase spatial distribution: at a fixed operating condition, the increase of vapour quality determines an increase of convective contribution and the establishment of annular flow regime. The thickness of the annulus is inversely proportional to mean fluid velocity; thus, increasing the vapour quality the convective contribution increases. The effect of the increase in the mass flux and so of the fluid mean velocity, is to increase the HTCs as the Figure 2 a) clearly shows.

Comparing Figure 2 b) with the results in Figure 2 a), it is noticeable the increase in HTCs' values and the change in the trends in the whole range of vapour qualities, while keeping constant operating conditions. In particular, referring to $\mathrm{R} 744$, for a fixed operating condition, the HTCs abruptly increase to the highest value at low vapour quality achieving a peak; they keep constant till a vapour quality of almost $30 \%$ where a decrease occurs and then they remain almost constant or slightly decrease while completing evaporation. This trend is due to a relative influence of nucleate and convective contributions, different than that pertaining to R134a. About the thermophysical properties of R744 it is known that its low surface tension should enable a higher number of nucleating sites, should determine a lower bubble departure diameter and a higher bubble frequency. All these effects cause a higher weight of the nucleate contribution and a lower superheat at the wall for the bubble formation, increasing the range of vapour qualities where the nucleation occurs.

In addition to this higher nucleate contribution, probably for carbon dioxide there is a stronger convective contribution at low vapor qualities. For the operating conditions investigated, the flow regimes expected to occur are the slug and the intermittent according to one of the most used two-phase flow pattern map [7] and the spatial distribution of the vapour slugs has expected to be different than the corresponding one for R134a at the same operating condition and vapour quality.

At high vapor quality, the R744 experimental trend probably accounts also for an influence of the convection contribution different than that for R134a. As known, at the same saturation temperature, the $\mathrm{R} 744$ has a ratio between vapour and liquid densities much higher than that of R134a. As a consequence, at the same operating conditions, the variation in mean fluid velocity is reduced for R744 during evaporation and so the increase in HTCs with vapour quality due to the phase change should be less pronounced. However, the convective contribution is also related to the liquid thickness and so to the twophase flow regime: the greater density ratio of R744 determines also a greater liquid thickness in the annular flow regime and so a lower value of convective contribution and a smaller effect on nucleate boiling suppression. 


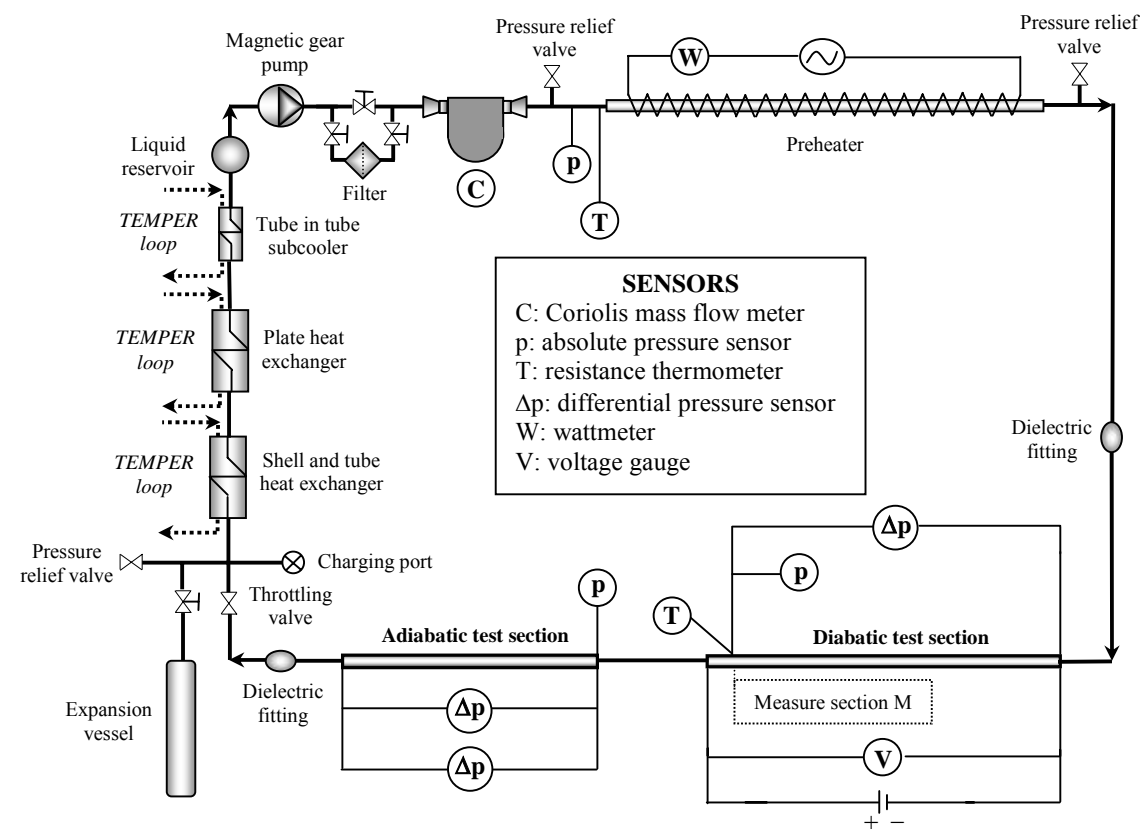

Figure 1. Experimental apparatus scheme.
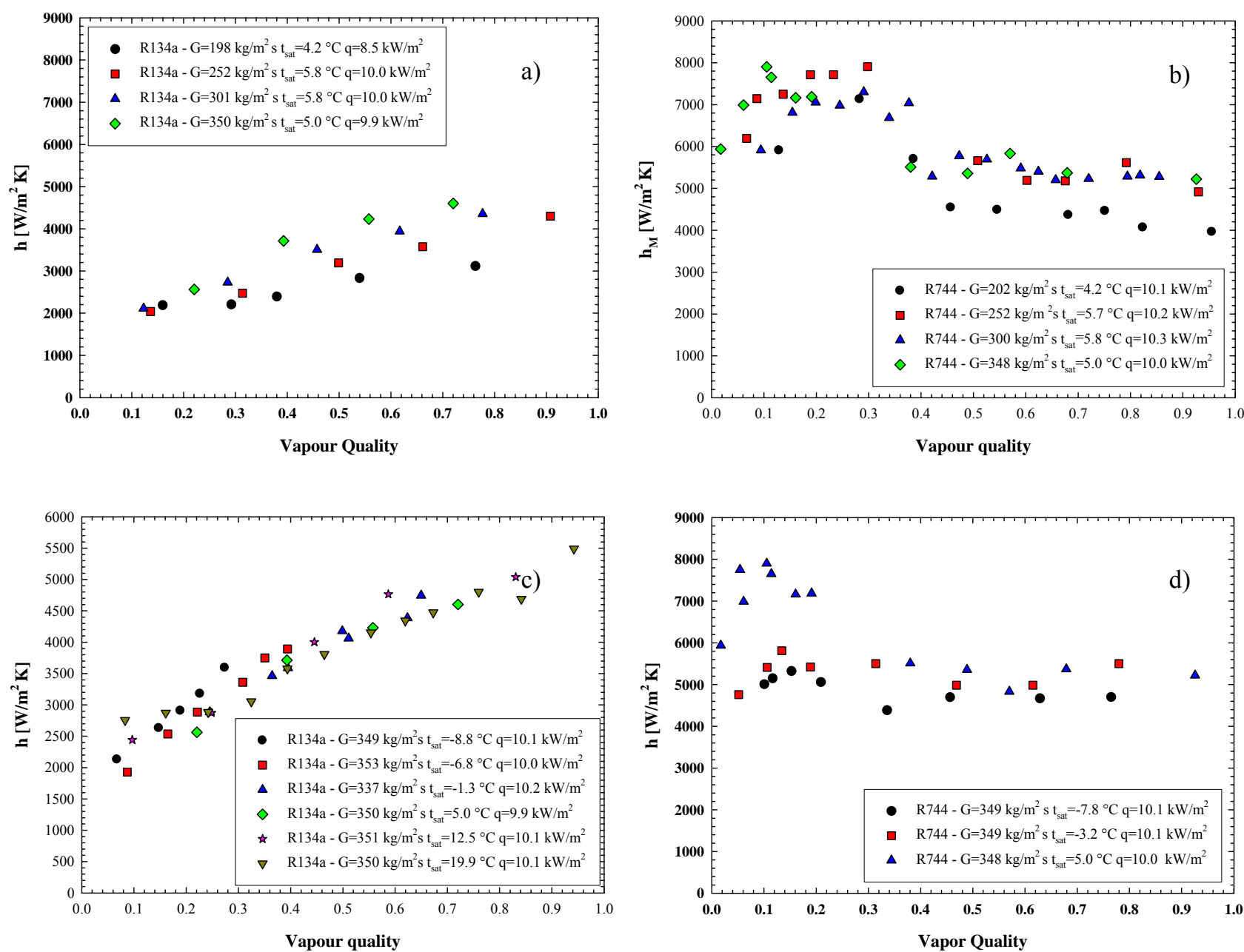

Figure 2. Flow boiling heat transfer coefficients for $\mathrm{q}$ (heat flux) equal to $10 \mathrm{~kW} / \mathrm{m}^{2}$ : at $\mathrm{t}_{\text {sat }}$ (saturation temperature) almost equal to $5.0{ }^{\circ} \mathrm{C}$ varying $\mathrm{G}$ (mass flux) between 200 and $350 \mathrm{~kg} / \mathrm{m}^{2} \mathrm{~s}$ for R134a [a)] and R744 [b)]; at G $=350 \mathrm{~kg} / \mathrm{m}^{2} \mathrm{~s}$ varying $\mathrm{t}_{\text {sat }}$ between $-9.0{ }^{\circ} \mathrm{C}$ and $+20{ }^{\circ} \mathrm{C}$ for $\mathrm{R} 134 \mathrm{a}$ [c) $]$ and between $-8.0^{\circ} \mathrm{C}$ and $\left.+5.0{ }^{\circ} \mathrm{C} \mathrm{R} 744[\mathrm{~d})\right]$. 
Figure 2 c) shows the HTCs of R134a as a function of the vapour quality varying the saturation temperature between $-8.8{ }^{\circ} \mathrm{C}$ and $+19.9{ }^{\circ} \mathrm{C}$, a heat flux equal to 10.0 $\mathrm{kW} / \mathrm{m}^{2}$ and a mass flux of $350 \mathrm{~kg} / \mathrm{m}^{2} \mathrm{~s}$. It is clearly shown that the trend and the values remain the same while varying the saturation temperature. In Figure 2 d) the same operating conditions are investigated for R744. It is possible to notice that the trend with respect to the vapour quality is the same that in Figure $2 \mathrm{~b}$ ). Increasing the saturation temperature there is an increase in the peak value and in the vapour range corresponding to the increase of HTCs. This is consistent with the fact that increasing the saturation temperature the ratio between vapour and liquid densities increases.

About the influence of the heat flux at the heated wall, from the experimental results not reported here it was showed that both for R134a and R744 the heat transfer coefficients increase at increasing the heat flux, in the whole range of vapor qualities.

\section{Conclusions}

In this paper new experimental data for heat transfer coefficients (HTCs) during flow boiling of R134a and $\mathrm{R} 744$, in operating conditions commonly encountered in commercial refrigeration, are presented. The main results of this work are here synthesised:

- the HTCs of R744 are always higher than those of $\mathrm{R} 134 \mathrm{a}$ at the same operating condition;

- the HTCs of R134a are increasing with vapour quality. The values are strongly dependent of the mass flux and nearly independent of saturation temperature;

- the trends of HTCs for R744 showed a peak at low vapour qualities and then an almost constant trend at high vapour qualities. The values are almost independent of mass flux and strongly dependent of saturation temperature at low vapour qualities.

About R744 a first interpretation of experimental data based on thermophysical properties comparison and flow regimes transitions was presented.

However a comprehensive interpretation of heat transfer characteristics still requires more experimental data for wider ranges of operating conditions, more information about flow regime transitions and a deep analysis of heat transfer coefficient spatial distribution.

\section{References}

[1] EC Regulation 2037/2000, 2000.

[2] UNEP, Report of the refrigeration, air - conditioning and heat pumps technical options committee, 2006.

[3] Cavallini A., Zilio C., Carbon dioxide as a natural refrigerant, 5th International Congress on Sustainable Energy Technologies, Vicenza, Italy, 2006.

[4] De' Rossi F., Mauro A. W., Rosato A., Confronto delle perdite di carico dell'R744 e dell'R134a durante l'evaporazione in convezione forzata, Proceedings of $63^{\circ}$ Congresso Nazionale ATI, Palermo, 2008.

[5] Moffat R. J., Describing uncertainties in experimental results, Experimental Thermal Fluid Sciences 1 (1988) 3-17.

[6] Lemmon E. W., Mc Linden M.O., M.L. Huber, NIST Standard Reference Database 23, Version 7.0, Physical and Chemical Properties.

[7] Cheng L., Ribatski G., Moreno Quibén J., Thome J. R., New prediction methods for $\mathrm{CO}_{2}$ evaporation inside tubes: Part I - A two-phase flow pattern map and a flow pattern based phenomenological model for two-phase flow frictional pressure drops, International Journal of Heat and Mass Transfer 51 (2008) 111-124. 